\title{
CONFERENCIAS
}

\section{PAULMIER DE GONNEVILLE E OS ÍNDIOS DO BRASIL EM $1504\left(^{\star}\right)$.}

Que a viagem do francês Paulmier de Gonneville não adquiriu ainda verdadeiramente direito de cidade - pelo menos tanto quanto certas outras relações de viagens devidas a autores não portuguêses - entre as fontes da história dos primeiros contactos entre os europeus e os índios do litoral brasileiro, é o que revela o exame da recente, e aliás excelente, Historiografia del Brazil. Siglo XVI de José Honório Rodrigues (1). No que tange à historiografia estrangeira de lingua francesa, o Autor se ocupa evidentemente das Singularitez de la France Antarctique de Thevet, fruto duma estadia de três meses entre 10 de novembro de 1555 e 31 de janeiro de 1556, e da Histoire d'un voyage faict en la Terre du Brésil de Jean de Léry que passou no Brasil onze meses entre o início de março de 1557 e 4 de fevereiro de 1558 (2); mas năo menciona a viagem de Gonneville que se coloca, todavia, mais de meio século antes. E' verdade que se pude dizer em abôno de Honório Rodrigues que essa viagem não foi objeto duma relação pròpriamente dita, mas é conhecida por um documento administrativo. Sem dúvida é isso que explica o fato do escritor brasileiro não tratar dela ex professo; não é menos significativo não fazer êle em nenhuma parte a menor alusão a essa viagem.

Todavia, J. F. de Almeida Prado já se tinha interessado por Gonneville nos seus Primeiros Povoadores do Brasil (1500-1530) (3). Coloca ai primeiramente a viagem em 1502 (4), mas diz em seguida que o sul do Brasil (Santa Catarina) teria sido atingido em fins de 1504 (5). Assinala também o ataque do navio pelos piratas em face das costas da França, durante a viagem de volta, ataque que causou a perda do jornal de bordo, assim como dos desenhos de um membro da expediçáo de nome Nicolas Lefevre, e acrescenta:

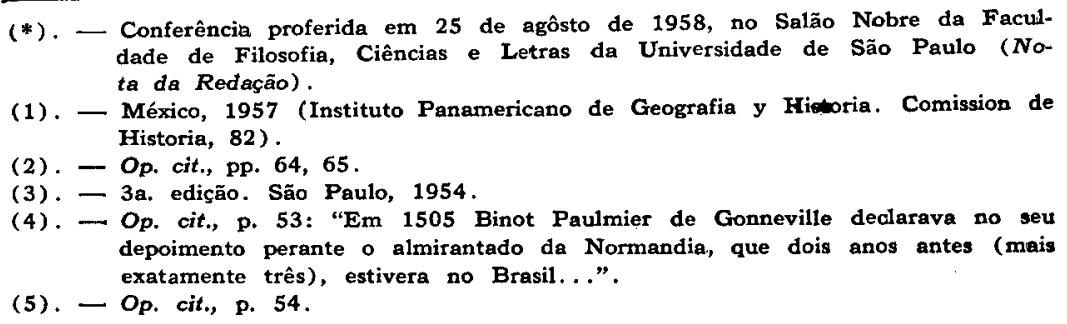


"Fácil imaginar o valor informativo de tão preciosos documentos sôbre o Brasil de 1503" (6).

Assinalemos de passagem que aqui é mencionada uma terceira data: 1503 .

Voltando mais adiante sôbre a declaração de Gonneville (7), Almeida Prado publica trechos referentes ao aspecto e o gênero de rida dos indígenas. Separa êsses dados em dois grupos, distinguindo - segundo o texto francês - se êles se referem a uma escala ao sul do Capricórnio ou a duas outras ao norte do trópico. Como para o primeiro grupo Gonneville não diz que os índios eram antropófagos, Almeida Prado deduz que êles habitavam a região entre Cananéia e as lagunas do sul, onde a antropofagia era pouco praticada. Quanto aos testemunhos relativos à zona ao norte do Capricórnio, não tenta localizá-los (8). Em nenhuma parte pretende determinar a que tribos pertenciam os indigenas encontrados.

$O$ texto da Relation authentique de Gonneville foi publicado de novo, há uma dezena de anos, por Ch. A. Julien (9) segundo a edição anterior de D'Avezac (10). Êsse texto foi estabelecido em 1658 nas seguintes circunstâncias. O índio brasileiro Essomericq, levado por Gonneville à França, ai desposou uma parente dêste, que lhe legou, além do seu nome, uma parte dos seus bens. Em 1658, os descendentes de Essomericq foram considerados como estrangeiros (aubain) ou oriundos de estrangeiro pelos arrendatários do direito de sucessão de advenas (aubaine), que lhes reclamavam o pagamento dêsse impôsto. Para se subtrairem a essa imposição, tentaram provar que o seu antepassado brasileiro não se tinha fixado em França por sua livre e espontânea vontade e reclamaram, em conseqüência, do Almirantado de Ruão um extrato dos registros dêsse tribunal no ano de 1505, onde figurava efetivamente uma

"Declaration du vegage du capitaine Gonneville et de ses compagnons ès Indes, et remerches ( = remarques) faites au dit vegage, baillées vers justice par le capitaine et ses dits compagnons jouste qu'ont requis les gens du roy nostre sire et qu'enjoit leur a été" (11).

\footnotetext{
(6). - Op. cit., p. 64 .

(7). - Cf. abaixo p. 258.

(8). - Op. cit., pp. $182-185$.

(9). - Les Français en Amérique pendant la première moitié du XVIe siècle (Colonies et empires. 2e sér. Les classiques de la colonisation, t. I), Paris, 1946, pp. 25-26.

(10). - Campagne du navire "L'Espoir" de Honfleur, 1503-1505. Relation authentique du voyage du capitaine de Gonneville es notvelles terres des Indes (Paris, 1859). Texto, pp. 87-115.

(11). - Julien, p. 25 e n. 1. O extrato começa assim: "Les giens tenants l'admirauté de France au siège général de la Table de Marbre du Pallais à Rauen sçavoir faisons que des registres du greffe dudit siège, année mil cinq cens cing, a esté extrait et collationé à la minutte originale ce qui ensutit". A "Table de Marbre" agrupava o almirantado, a condestáblia e jurisdição das águas e florestas.
} 
Dissemos, com efeito, que durante a viagem de volta, Gonneville foi atacado por um pirata. Isso se passou perto de Jersey e Guernesey, e o pirata era um inglês de Plymouth chamado Edward Blunt, ao qual se juntou posteriormente um bretão chamado Maurice Fortin. O navio de Gonneville deve ter naufragado, mas foi pilhado antes de afundar completamente. Gonneville e os "burgueses" que tinham armado o navio apresentaram queixa. Foi então que os juízes do Almirantado

"pour la rareté dudit voyage et jouste les ordennances de la marine portantes que à la justice seront bailléz les journaux et déclarations de tous voyages de long cours",

reclamaram, em lugar do jornal de bordo perdido, a declaração que assinaram Gonneville e dois dos "burgueses" do navio no dia 19 de junho de 1505. E' essa declaração copiada e conferida em 1658, que permitiu aos descendentes de Essomericq não pagar o impôsto de advena. Ela oferece tôdas as garantias de autenticidade.

Após diversas peripécias, que não nos reterão aqui, o Espoir era êsse o nome do navio - tinha abordado a costa brasileira em 6 de janeiro de 1504. E' pois para êsse ano que valem as passagens relativas aos índios de que devemos nos ocupar agora (12).

$O$ navio penetrou num rio

"qui est quasiment comme celle de l'Orne" (13)

na Normândia. Segundo Avezac seria o antigo Rio Alagado, embocadura setentrional do Rio São Francisco do Sul (14). E' necessário convir que a hipótese é gratuita, porque nada no texto permite formular a menor suposição nesse sentido.

Seja como fôr, os franceses permaneceram no seu ancoradouro até julho.

"Pendant leur demeurée en la dicte terre, ils conversoient bonnement avec les gens d'icelle".

Segundo Avezac, seguido por Julien, tratar-se-ia aqui da tribo guarani dos carijós (cario, chandul), os guaranis que ocupavam, no inicio do século XVI, todo o litoral entre a Barra de Cananéia e o Rio Grande do Sul. Os indigenas se mostraram muito sociáveis

"estans lesdicts Indiens gens simples, ne demandant qu'à mener joyeuse vie sans grand travai, vivant de chasse et de pesche, et de ce que leur terre donne de soy, et d'aucuns légumages et racines qu'ils plantent; allant my-

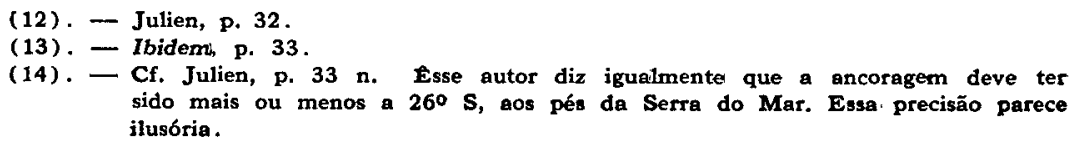
sido mais ou menos a $26^{\circ} \mathrm{S}$, aos pés da Serra do Mar. Essa. precisão parece ilusória. 
nuds, les jeunes et communs spéciallement, portant manteaux, qui de nattes déliées, qui de peau, qui de plumasseriès... avec manière de tabliers ceints par sus les hanches, allans jusque aux genoux aux hommes et aux femelles à my-jambe".

O enfeite, o armamento e os toucados são descritos em traços relativamente precisos.

"Et portent les femelles colliers et brasselets d'os et coquilles; non l'homme qui porte au lieu arc et flesche ayant pour vireton un os proprement asséré, et un espieu de bois très dur brûlé et asséré par en haut; qui est toute leur armure. Et vont les femmes et filles teste nue, ayant leurs cheveux gentiment teurchéz de petits cordons d'her.bes teintes de couleurs vives et luisantes. Pour les hommes, portent longs cheveux ballants, avec un tour de plumasses hautes, viveteintes et bien atournées".

O habitat é objeto de indicações notàvelmente concretas:

"Item disent le pays être peuplé entre deux. Et sont les habitations des Indiens par hameaux de trente, quarante, cinquante ou quatrevingts cabanes, faites, en manieres de halles, de pieux fichéz joignant l'un l'autre, entrejoints d'herbes et feuilles, dont aussi lesdits habitants sont couverts; et y a pour cheminée un trou pour faire en aller la fumée. Les portes sont de bastons proprement liéz; et les ferment avec chefs de bois, quasiment comme on fait en Normandie, aux champs, les estables. Et leurs lits sont de nattes douces pleines de feuilles ou plumes, leurs couvertes de nattes, peaux ou plumasseries; et leurs ustenciles de ménage de bois, même leurs pots à bouillir, mais induis d'une manière d'argille bien un doigt d'espais, ce qui empesche que le feu ne les bruslast".

Quanto à organização social, eis como o documento a apresenta:

"Ils disent avoir remerché ledit pays estre divisé par petits cantons, dont chacun a son roy; et quoy que lesdits roys ne soient guières mieux logéz et accoustréz que les autres, si est-ce qu'ils sont moult révéréz de leurs sujets; et nul si hardi ose refuser leur obeir, ayans, iceux pouvoir de vie et de mort sur leurs sujets".

Segue-se, então, um exemplo dêsse poderio do chefe:

"Un jeune fils de dix-huit à vingt ans, en certain chaud dépit, avait donné un soufflet à sa mère; ce qu' ayant sceu son seigneur... il le fit jetter à la rivière, une pierre au col, appelez à cry publique les jeunes fils du 
village; et si nul n'en put obtenir remission, ni même la mère".

Esse "rei" se chamava Arosca, nome do qual os lingüistas talvez possam tirar partido, da mesma maneira que aquêle de Essomericq, já citado, e de Namoa, um. outro índio do mesmo grupo. Ele reinava sôbre uma dúzia de aldeias que tinham cada uma seu chefe particular. A extensão de

"son pays estoit de bien une journée".

As relações dêsses indígenas com os europeus foram excelentes.

"Item disent que quand les Chrétiens eussent esté anges descenduz du ciel, ils n'eussent pu estre mieux chéris par ces pauvres Indiens".

Aqui o editor assinala que Simão de Vasconcelos considerava os carijós como

"la meilleure nation du monde",

o que, bem entendido, não prova de modo algum que se tratava mesmo de carijós na declaração de Gonneville.

No que se refere a trocas, um único produto local parece merecer a atenção de quem queira localizar geogràficamente e ètnicamente o lugar da estadia dos franceses. Trata-se das "raízes para tingir" (racines à teindre) (15). Infelizmente a indicação é bem vaga.

A 3 de julho, após uma estadia de 6 meses e 3 dias, os franceses deixaram seus amigos indios e navegaram em alto mar até 10 de outubro. Sofreram muito com o escorbuto e finalmente decidiram voltar para a América. Eis como o texto narra o ocorrido:

"Or passez le Tropique Capricorne, hauteur prise, trouvaient estre plus éloignéz de l'Affrique que du pays des Indes occidentales où d'empuis aucunes années en ça les Dieppois et les Malouinois et autres Normands et Bretons vont quérir du bois à teindre en rouge, cotons, guenons et perroquets et autres denrées: si que le vent d'Est, qu'ils ont remerché régner coustumierement entre ledit Tropicque et cil de Cancre, les y poussant, fut d'unanimité délibéré d'aller querir cettuy pays, affin estout de se charger des susdites marchandises, pour rescaper les frays et voyage".

Não nos deteremos no comércio dos maluinos e dos diepenses no Brasil antes de 1504, mas faremos notar que o conhecimento dessas rotas atlânticas, da qual faz prova a equipagem do L'Espoir, se explica, notàvelmente, pela presença a bordo de dois portuguêses, chaniados Batiam Moura e Diègue Cohinto (16) (sem dúvida Diogo Cou-

(15). - Julien, p. 36 .

(16). - Ibidem, p. 26. 
tinho) que se deixaram corromper por alto preço em Lisboa e tinham estado todos os dois nas fndias, talvez com Cabral. Aliás, tanto quanto o descobridor português do Brasil, era a fndia que Gonneville tinha inicialmente querido atingir. Não tinha renunciado a isso senão depois da morte do seu principal piloto - sobrevinda ao sul do Cabo da Boa Esperança - e depois de violentas tempestades que duraram muitas semanas. Como o L'Espoir procurava terra para abastecer-se de água doce, víveres e mercadorias e os encontrou no Brasil (17), há sérias razões para acreditar que os dois portuguêses que estavam a bordo, valiam tanto quanto as informações, sem dúvida bem vagas, provenientes de

"Dieppois, Malouinois et autres Normands et Bretons".

Admite-se geralmente que a segunda abordagem teve lugar ao norte do Trópico; mas não foi porque em pleno Oceano o L'Espoir tivesse passado o Capricórnio que êle abordou necessàriamente de novo o Brasil ao norte. Aqui os franceses

"trouvèrent des Indiens rustres nuds comme venants du ventre de la mère, hommes et femmes; bien peu $y$ en ayant couvrant leur nature; se peinturent le corps, signamment de noir; lèvres trouées, les trous garnys de pierres vertes proprement polies et aggencées; incisés en maints endroits de la peau, par balafres, pour paroistre plus beaux fils, ébarbez, my-tondus. Au reste, cruels mangeurs d'hommes, grands chasseurs, pescheurs et nageurs; dorment pendus en lits faits comme un rets, s'arment de grands arcs et massues de bois, et n'ont entre eux ne roy ny maistres".

Julien observa que essa passagem apresenta a primeira descri. ção em francês e por um francês, do selvagem nú, com o corpo enegrecido pelo suco do genipapo ou cheio de cicatrizes, trazendo batoques de pedra verde nos lábios, praticando o canibalismo e vivendo na anarquia (18). E acrescenta que se a escala teve lugar nas proximidades de Pôrto Seguro - o que do texto nada permite deduzir - ela deve ter tido lugar entre os tupiniquins que ocupavam a costa desde Cananéia ao norte, até o Rio São Mateus ao sul (19). A declaração acrescenta que os indios

"font leur pain et breuvage de certaines racines".

Eles já tinham visto cristãos

"comme estoit. apparent par les denrées de chrestienneté que lesdits Indiens avoient".

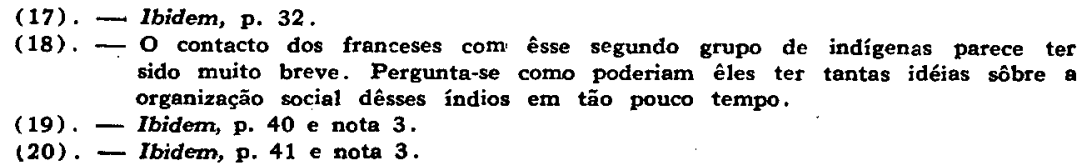


Alguns franceses que foram à terra foram mortos ou feridos, o que levou Gonneville a deixar imediatamente o lugar e

"amonter la coste bien cent lieues plus amont".

Os franceses encontraram aí

"des Indiens pareils en façon"

que Julien supõe tratar-se dos tupinambás da região da Bahia (20).

"Et là, pendant que la navire y demeura, elle fut chargée de vivres et des marchandises dudit pays prédéclarées (21), en la quantité plus à plein et en détail contenue en la plainte et douléance baillée à justice contre cils qui ont pillé la navire".

Gonneville deixou essa região

"entre la Saint Thomas et Noël cinq cens quatre" (22),

isto é, entre 21 e 25 de dezembro de 1504. Dois índios tinham sido levados à fôrça

"mais dèz la première nuit ils se coulèrent en la mer, estant lors la navire à plus de troys lieues de coste; mais ces gallands sont si bons nageurs que tel trajet ne les effrite".

Trata-se em seguida da desembocadura (debouquement), manobra consistente em sair dum passo. Que Avezac tenha pensado que semelhante manobra só possa ter sido concebida ao sair da Bahia (23) parece, pelo menos, aśsombroso.

Eis o que o texto da declaração de Gonneville nos diz sôbre os três grupos de índios da costa brasileira. As tentativas de localização geográfica dêsses grupos indigenas, aos quais se entregou Avezac e que foram retomados por Julien, não parecem muito convincentes. Vejamos se a antropologia histórica pode nos ajudar.

Notemos inicialmente que os franceses conheceram melhor os indios do primeiro grupo - o mais meridional - do que os outros dois. Permaneceram durante seis meses entre os súditos do rei Arosca. Penetraram também no interior das terras (24).

No que se refere à localização dos grupos indígenas com os quais teriam havido os contactos dos franceses, a precisão e concordância não é sempre muito grande entre os autores que dêles se ocuparam. $O$ historiador A. Marchant os situa da seguinte maneira:

(21). - Cf. abaixo, p. 269.

(22). - Julien, p. 41 e nota 4 .

(23). - Ibidem, p. 42, n. 2 .

(24). - "Disent outre avoir entré dans ledit pays bien deux journées awant et le long des costes davantage tant a dextre 'que a senestre". Julien, op. cit., p. 34. 
"The Carijos lived in the vicinity of and to the south of São Vicente. The Tupinambás, strongest around Rio de Janeiro, were also on the northern coast between the São Francisco River and the Rio Grande do Norte. The Tupiniquins occupied the rest of the coast, between the Carijós of São Vicente and the Tupinambás of Rio de Janeiro, and between Rio de Janeiro and the São Francisco, with a great number around Bahia" (25).

L. Pericot y Garcia coloca os tupinambás ao sul do São Francisco até $14^{\circ}$ de latitude sul, os tupiniquins ao sul dêstes até o Rio São Mateus, os carijós entre a ilha de Santa Catarina e o Rio Cananéia (26). Essas localizações, e mais aquelas que citamos quando analisamos o texto de Gonneville, deixam evidentemente uma certa flutuação que se adiciona ao vago geográfico que caracteriza a declaração de Gonneville. Nos resta pois uma possibilidade: comparar as características atribuidas aos três grupos mencionados por Gonneville com os resultados da antropologia histórica.

Essa tarefa é a mais fácil para o grupo meridional. Segundo Gonneville êsses indios viviam de caça e de pesca, daquilo que

"leur terre donne de soi",

legumes e raízes que êles plantam. Andam semi-nús, sobretudo os jovens e os

$$
\text { "communs", }
$$

mas trazem mantos de

$$
\text { "nattes déliées", }
$$

de pele ou de plumas, a

$$
\text { "manières de tabliers", }
$$

prêso nas ancas e indo até aos joelhos entre os homens e até ao meio das pernas entre as mulheres. Quanto aos enfeites, êles constituiam para as mulheres em colares e braceletes de osso ou de conchas. $O$ homem não os usava. Seu armamento consistia em arco, flecha com ponta de osso acerada, chuço de madeira dura queimada e aguçada na ponta. O penteado das mulheres era caracterizado pelo emprêgo de cordões de ervas pintadas de côres vivas e brilhantes. Os homens tinham os cabelos Iongos com plumas de côres vivas. O povoamento é de densidade média. As aldeias tinham 30,40, 50, 80 cabanas dispostas em círculo (halles), feitas de paus, com ervas e fôlhas nos interstícios. Essas cabanas tinham um buraco para a saida da fu-

(25). - From barter to slavery. The economic relations of Portuguese and Indians in the settlement of Brazil (1500-1580) (John's Hopkins Studies in Historical and Political Science, 1942), p. 65.

(26)..- America indigena, t. I. EI hombre americano. Los pueblos de America (Barcelona, 1936), p. 643 . 
maça, portas feitas de varas e fechando com trancas de madeira. Os indigenas dormiam em esteiras cheias de fôlhas e penas. Cobriamse com mantos de peles ou de plumas. Os utensilios de cozinha eram de madeira, cobertos de argila cozida naqueles que serviam para cozinhar os alimentos. A região era dividida em pequenos cantões cada um com os seus chefes. O de Arosca comportava uma dezena de aldeias, cada uma com o seu chefe particular. Êsses chefes aplicavam a pena de morte, notadamente o afogamento.

Vejamos se êsses traços convém aos carijós descritos pelos antropólogos.

Carijó é, sabe-se, o nome antigo dos guaranis. Os carijós desciam no século XVI até as ilhas do Rio da Prata e até o delta do Paraná. Segundo A. Métraux (27) os carijós se alimentavam de caça e pesca, assim como de frutos selvagens e de produtos da sua horticultura. Isso concorda bem com as informações fornecidas por Gonneville, tanto mais que segundo êste, diferentes tubérculos e leguminosas intervinham na sua horticultura. As plantas cultivadas eram a mandioca, o milho, a batata doce, favas, a leguminosa mbacucu, a banana, o mamão, a melancia. Entre as plantas selvagens o pinhão da Araucaria brasiliensis desempenhava um papel de primeira ordem. Sem dúvida o mel selvagem deve ser computado igualmente entre os produtos que

"leur terre donne de soi",

como diz Gonneville. E' interessante notar que a declaração atribui uma importância particular à agricultura que era mais desenvolvida entre os antigos carijós do que entre os seus descendentes atuais, os cainguás. A baixela que êstes usavam era ainda recentemente de madeira como a dos carijós.

Segundo o Handbook of South American Indians (28) uma aldeia carijó antiga consistia em casas retangulares, o que concorda muito bem com as "halles" mencionadas por Gonneville. Dos postes do teto arqueado ou abaulado igualmente fala Métraux. As ervas e as fôlhas de palmeira que entram na construção, segundo Métraux, são igualmente mencionadas por Gonneville. Êste cita também as portas, das quais Métraux nos diz que havia uma de cada lado das casas comunitárias. Elas fecham, nos diz Gonneville, com trancas de madeira e são feitas de varas. Há, entretanto, um traço pelo qual a descrição da aldeia em Gonneville difere muito daquela que dá Métraux. Este fala de quatro a oito grandes casas retangulares, quando Gonneville dizia existir 30, 40, 50, 80 cabanas em forma de "halles". Cremos que a importância dessa informação não foi sufi cientemente notada. Convém, com efeito, não esquecer que as fontes antigas, sôbre as quais nos apoiamos habitualmente, são muito posteriores a Gonneville e que, se as aldeias comportam mais tarde menos casas, isso é sem dúvida devido à influência da penetração dos bran-

(27). - Handboak of South American Indians, Washington, 1948, pp. 80 e seg. (28). - Ibidem, p. 82 . 
cos e ao deslocamento e desaparecimento da população indigena. Na época de Gonneville nenhuma aculturação havia ainda agido. Cremos igualmente que a descrição das casas que dá Gonneville pode ser considerada como muito fiel, apesar das dúvidas que formula sôbre dois pontos A. Métraux no seu livro sôbre a civilização material dos tupi-guaranis (29). Esse distinto etnógrafo duvida que Gonneville estivesse certo mencionando, nas casas dos indigenas entre os quais permaneceu, um

$$
\text { "trou pour faire en aller la fumée", }
$$

por que, diz êle

"comme il (Gonneville) ajoute plus bas que les portes étaient fermées avec une serrure, il est légitime de douter de l'exactitude des ses souvenirs".

Não cremos nisso porque inicialmente Gonneville não diz que as portas se fechavam com uma fechadura, mas

"avec clefs de bois, quasiment comme on fait en Normandie aux champs, les étables".

Eis uma lembrança duma singular precisão, acompanhada duma comparação muito concreta. A fechadura se reduz pois a um pedaço de pau passado num outro que o fecha, ou simplesmente um único pedaço de madeira ligado à porta e tendo apôio na parede em posição fechada, se se trata duma porta fechando pelo lado de dentro. Por outro lado não convém esquecer que a declaração foi feita imediatamente depois da volta de Gonneville. Se as minúcias relativas às portas e às chaves de madeira merecem todo crédito, é certo naquilo que se refere ao número de casas, característica mais notável e mais fácil de observar. Pensamos, pois, que nos encontramos aqui diante dum testemunho que permite ver que as fontes ulteriores pelo menos para certos grupos indigenas - já não descrevem mais as situações correspondentes à época precedente à chegada dos bran$\cos$ e que é neceșsário pois concluir que as aldeias carijós eram muito mais povoadas no início do XVI século do que depois.

Quanto às vestes, trata-se segundo Gonneville, de mantos de peles que Hans Staden (II, 2) notou também entre os carijós; pois existem mantos de penas cujos exemplares figuram em diversas coleções. Não encontramos outras menções de mantos de

\section{"nattes déliées"}

de que fala a Relation. Os aventais são evidentemente tangas, mais longas entre as mulheres do que entre os homens. No caso das mulheres, trata-se, sem dúvida de "tipoys" de algodáo, pois sabemos que os carijós colhiam o algodão para fazer suas vestes (30). Sa-

(29). - Paris, 1928, p. 52.

(30). - Ibidem, p. 175. 
be-se que êsses "tipoys" se generalizaram sob a influência dos missionários.

Os colares de conchas eram correntes e os ossos também como peças de enfiar (31). Os braceletes de ossos são igualmente descritos por Léry e nós sabemos que haviam também os de conchas (32). E' curioso, todavia, notar que Gonneville assinala que os homens não traziam êsse ornamento. Isso concorda no caso dos braceletes com o que diz Léry, mas os testemunhos referentes aos colares usados pelos homens são freqüentes em muitos autores antigos (33).

Entre as armas a flecha tendo por virotão um osso acerado apresenta um pequeno problema. O têrmo virotão é, sem dúvida, empregado por Gonneville por analogia com a flecha da besta chamada por êsse nome. Ela era armada com um ferro piramidal e possuia lâminas oblíquas que a empenavam e lhe imprimiam um movimento de rotação que tornava a ferida mais penetrante. A palavra "vireton" ou "viretou" designava também - mais antigamente - uma espécie de flecha cuja pena estava disposta em espiral, o que a fazia virar no trajeto. Sem dúvida, trata-se, em Gonneville, duma emplumadura denteada em osso. Conhece-se flechas cainguás com denteaduras dum lado (34). Daí talvez venham os ossos únicos de que fala Gonneville.

O chuço de madeira queimado e aguçado na ponta não parece uma lança, arma aliás muito pouco divulgada antigamente (35), mas talvez uma maça, não do tipo tupinambá entumecido na ponta, mas antes do tipo cainguá, como o exemplar reproduzido por Métraux no seu livro sôbre a Civilisation matérielle (36); o que, diga-se de passagem, convém aliás muito mais ao grupo carijó do qual descendem os cainguá.

As mulheres

"ayant leurs cheveux gentiment teurchéz de petits cordons d'herbes teintes de couleurs vives et luisantes"

evocam uma forma menos elaborada das corôas de palha com tijelas de côres variadas que se encontra, segundo Hintermann, entre as auetö (37). A

$$
\text { "tour de plumasses hautes" }
$$

dos homens é evidentemente um diadema igual ao usado ainda pelos cainguás, segundo Kurt Nimuendajú (38).

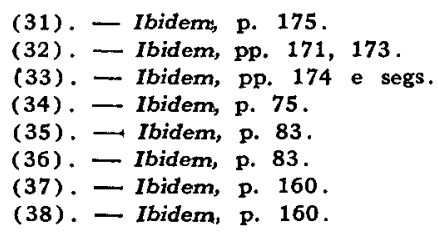


Já falamos do habitat, sublinhando a originalidade do testemunho trazido por Gonneville a êsse propósito. No que se refere ao mobiliário, os cainguás deitavam-se ainda recentemente sôbre esteiras de fôlhas (39), como os índios de Gonneville. O fato dêstes terem também cobertas de esteiras, peles ou penas mostra que êles estavam fixados numa região meridional.

Quanto à organização política e social, ela é caracterizada pela existência de

$$
\text { "petits cantons dont chacum a son roy". }
$$

O de Arosca comportava uma dezena de aldeias, que tinham cada uma um chefe particular. O rei era talvez uma espécie de shaman, pois que o vemos intervir no castigo dum delito, como o faziam os shamans dos cainguás (40). Além do mais, o modo da execução que êle aplicava, o afogamento, é atestado aliás no século XVI (41).

Os franceses fizeram trocas com os indígenas que encontraram em primeiro lugar e entre os quais permaneceram por mais tempo. Èstes lhes forneceram principalmente

\section{"racines à teindre"}

Quais? Nada nos permite dizer. Guardemos, em todo o caso, que o comércio parecia ser entre êles uma atividade antiga e costumeira.

No que se refere ao primeiro grupo descrito por Gonneville, tudo indica que temos de nos haver com os carijós, tanto mais que muitos traços assinalados por Gonneville podiam se observar ainda recentemente entre os cainguás, seus descendentes modernos. No conjunto, as informações relativas à antropologia cultural histórica, que se pode deduzir do texto da Relation, são muito mais concretas, e muito mais úteis para a identificação do grupo que os vagos dados geográficos que fornece êsse documento. Além do mais, a Relation - que se coloca muito pouco tempo depois da descoberta de Cabral, mais ao norte, pois que ela se relaciona com 1504, e que precede de mais de meio século Thevet e Léry (1555-1558) - permite colher certos traços, notadamente em matéria de habitat, que estão já alterados pela aculturação nas fontes ulteriores. E' pois evidente que a aproximação crítica entre os dados da antropologia cultural e os dum documento histórico como a Relation de Gonneville, apresenta ao mesmo tempo um interêsse para a história das civilizações indigenas antes de sua aculturação, para a história da descoberta e para aquela mesma história da colonização ulterior com tôdas suas conseqüências. Essa aproximação de disciplinas, muitas vêzes demasiadó separadas, impõe-se por tôda a parte pelo estudo dos primeiros contactos dos europeus com as populações indígenas. Aqui se faz necessário retomar todos os textos que se relacionam com o problema -

(39). - Ibidem, p. 150.

(40). - Handboak of South American Indians, t. IIr, p. 86 .

(41). - C. Lévi-Strauss, Tristes tropiqures, (Paris, 1955), p. 383. 
sob qualquer aspecto e em qualquer época - colocando-se nesse ponto de vista. Certamente, faz-se semelhantes aproximações, mas não sistemàticamente e demasiado exclusivamente a propósito de relaçóes mais modernas cujo conteúdo antropológico é mais rico, mas, de qualquer modo, menos puro, porque a aculturação já desempenhou o seu papel. Da massa dos relatórios dos viajantes antigos, que os etnógrafos consideraram como uma espécie de fundo comum de informações, sem se apegar sempre suficientemente à sua data, é necessário destacar, cada vez que fôr possível, os relatórios concernentes aos primeiros contactos, submetendo-os a uma investigação cerrada, ao mesmo tempo do ponto de vista histórico e antropológico. Essa observação apresenta, cremos, um alcance metodológico geral.

$O$ valor das observações que se pode fazer sôbre os dois outros contactos dos franceses de Gonneville com os indígenas brasileiros não é menor, porque, no caso do segundo grupo, a declaração diz expressamente que êles já tinham visto europeus

"comme estoit apparent par les denrées de chrestienneté que les dits Indiens avoient" (42).

Quando da terceira escala nada de semelhante é mencionado, mas, como trata-se de

"marchandises du-dit pais",

isto é, sem dúvida, do

"bois à teindre en rouge (pau brasil), cotons, guenons et perroquets"

de que falamos mais acima e que outros já tinham procurado (43), parece que a aculturação já tinha, lá também, exercido uma certa ação.

Os índios do segundo grupo não estavam vestidos, e sabemos que, salvo os carijós, isso era o caso de tôdas as tribos tupi-guaranis. Tinham o corpo pintado, sobretudo de negro, e estavam tatuados. Eram pilados (sem barba) e

"my-tondus",

isto é, sem dúvida tinham os cabelos cortados na testa à maneira tupinambá (44). E' verdade que o costume de raspar tôda a cabeça ou uma parte desta era muito comum e se encontrava em familias lingüisticas e em grupos étnicos muito diferentes (45). Os batoques verdes para os lábios eram reservados aos adultos machos entre os tupinambás (46), e são igualmente atribuídos aos homens por Gonneville (47). As macas, semelhantes às rêdes, são igualmente um

(42). - Cf. acima, p. 262.

(43). - Cf. acima, p. 263.

(44). - Métraux, Civilisations matérielle, p. 180 .

(45). - Ibidem, p. 181 .

(46). - Ibidem, p. 163.

(47). - Cf. acima, p. 262. 
traço tupinambá (48), da mesma maneira que os grandes arcos (49) e as maças de madeira (50). Que os indígenas não tinham

$$
\text { "ne roy ny maistres" }
$$

parece um produto da fantasia de Gonneville; já assinalamos que 0 seu contacto com êsse segundo grupo tinha sido muito curto para lhe permitir observações sérias sôbre assuntos dessa natureza (51). Esses indigenas faziam

"leur pain et breuvage de certaines racines".

Trata-se, sem dúvida de farinha de pão e de água à base de mandioca (52) ou, no segundo caso, de cauim de mandioca doce (53). Tudo isso é tupinambá mais do que qualquer outra coisa. Vê-se como a identificação do segundo grupo indígena visitado por Gonneville com os tupiniquins encontra poucas garantias na antropologia - já verificamos que os critérios geográficos que se querem utilizar no mesmo sentido são também muito fracos (54).

Resta o terceiro grupo, para o qual os dados antropológicos da Relation são nulos, salvo quando ela qualifica os indios que o compõem de

$$
\text { "pareils en façon" }
$$

aos precedentes. Parece que sôbre a base de critérios antropológicos mencionados por Gonneville para o segundo grupo e, por conseguinte, aplicáveis ao terceiro, pode-se considerar que o segundo e terceiro contactos dos franceses teve lugar com os tupinambás. Aqui igualmente a aproximação das disciplinas permite chegar a uma solidez maior na interpretação.

Concluimos pois que se importa não considerar os testemunhos antigos sôbre as sociedades indígenas como um único bloco não di.ferençado e se é necessário ligar uma importância particular aos testemunhos mais antigos anteriores à aculturação, como no caso dos carijós em 1504, é necessário igualmente tomar cuidado com interpretações históricas que não levam devidamente em conta os dados da antropologia. Sôbre a base dos dados desta última disciplina, parece bem que é necessário afastar os tupiniquins da lista das populações com as quais Gonneville tomou contacto em 1504. Por outro lado, parece também que é necessário levar em conta as infor-

(48). - Métraux, Civilisation matétielle, p. 60 .

(49). - Ibidem, p. 70 .

(50). 一 Ibidem, p. 80 .

(51). - Confira acima nota 18. A informação é aliás falsa para os grupos indígenas cia costa. Para os tupinambás ef. Handbook of South Americon Indians, $t$. III, p. 113 .

(52). - Métraux, op. cit., p. 102.

(53). - Ibidem, p. 112 .

(54). - Cf. acima, p. 262. 
mações muito antigas de Gonneville sôbre o habitat carijó para apreciar corretamente as transformaçōes dêste sob a influêencia da aculturação. O estudo dêsses casos particulares apresenta, repetimos, um interêsse geral do ponto de vista do método a aplicar ao estudo dos mais antigos textos referentes aos contactos entre europeus e indígenas.

\section{CHARLES VERLINDEN}

da Universidade de Gand. 